\title{
Electrophoretic Light Scattering
}

National Cancer Institute

\section{Source}

National Cancer Institute. Electrophoretic Light Scattering. NCI Thesaurus. Code C78868.

A technique for determining the zeta potential of a sample through the detection of the motion of dispersed particles relative to a fluid under the influence of an oscillating electric field. 